\title{
Employee Competency Mapping ${ }^{\#}$
}

\author{
P. Nagesh ${ }^{1 *}$, Sridevi Kulenur ${ }^{2}$ and Keerthana Jagadeesh ${ }^{3}$ \\ 'Professor \& Dean, JSS Centre for Management Studies, SJCE, Mysuru, Karnataka, India \\ ${ }^{2}$ Assistant Professor, JSS Centre for Management Studies, SJCE, Mysuru, Karnataka, India \\ ${ }^{3}$ JSS Centre for Management Studies, SJCE, Mysuru, Karnataka, India
}

\begin{abstract}
Over the years, change is playing a significant role with reference to organization systems, management principles, cultures and philosophy which has led to increase in highly skilled and knowledge based jobs across the globe. In the today's scenario, "Skill and Competency" are the main drivers of an organization's efficiency, effectiveness and performance at large. With increased significance to quality, operational efficiency and effectiveness, cost-reduction, high performance norms and managing with fewer and diversified employees than before by corporate, brings competency as the most important measure for all Human Resource related practices, decisions, initiatives and developmental aspects of an organization. Competency is a need of the hour for any sector aiming at refurbishing themselves to the current contemporary and competitive environment. Competency approach encourages employees to develop and enhance their competencies. The process of mapping the competencies of employee/employees is known as Competency mapping. Competency Mapping helps in knowing where an individual stands with respect to his skill sets i.e. his actual skills, expected skills and the skill gaps (Competency gaps). The present study aims at studying and analyzing the employee competencies of Training and Development Department of a typical manufacturing company in Mysuru, analyzing their expected skills and the actual skills, mapping them, identifying the competency gaps, analyzing the gaps to suggest necessary measures to reduce/bridge the competency gaps in employees.
\end{abstract}

Keywords: Competency, Skills, Competency Mapping, Competency Gaps

\section{Introduction}

Human resource management is a process of collaborative efforts put by employees and management as to accomplish both individual and organizational goals. Today, unless a firm's personnel relations are in order, it is extremely difficult to build an impressive financials. Since there is a need for highly skilled and knowledgebased employees, it calls for current and prospective skill mapping through proper HRM practices within an organization. Due to the international alignment, of the Indian organizations are witnessing a change in practices, processes, systems and organization cultures and philosophy. There is a requirement for multi-tasking in order to sustain in the competitive environment. Competency is a combination of knowledge, skill and attitude required to achieve high performance with effectiveness and efficiency. Competency Mapping is a process to know how competent the organization and its members are in this regard. Competency mapping recognizes the individual's strengths and areas for improvement and directs them towards career development aspects. It helps in identifying the competency gaps by comparing the expected set of competencies required to perform a task/job with the actual competency of an employee. Competency mapping has always been the most precise means for identifying the job, behavioral and personal competencies required for an individual to perform better.

\section{Literature Review}

Literature survey looks at the current and past theories that are behind the research subject. Several researchers

*Email: pnagesh1973@rediffmail.com

"Revised and modified version of the paper, presented in the $5^{\text {th }}$ International Conference on "Managing HR at the workplace, SDMIMD, December 2016. 
have addressed different methods and techniques for obtaining the competency maps and gap analysis. Let us have a brief look at few of them.

Yuvaraj, (2011) states that employee competency mapping has always been the most precise means for identifying the job, behavioral and personal competencies required for an individual to perform better. Rather than looking at employee competency mapping as rewards, all the stakeholders must realize the importance of competency mapping and should exercise it as an opportunity for sustainability.

Balaji \& Vimala, (2012) makes an attempt to study the competency mapping in Adecco Service Organizations at Chennai. The research identifies the difference between the performance of employees of the organization, identifies the competency gap of employees using competency mapping and provides some suggestions to bridge the gaps.

Kaur \& Kumar, (2013) states that management is required to concentrate on strategic use of human resources and it is significant for the organizations to successfully run the competency-based human resources management practices. The study describes how and to what extent competency mapping helps the organization to be more effective and efficient.

Jain, (2013) analyzes the factors of employee competencies like personal attributes, skills and knowledge and analyzes the gap with actual and desired skills and assesses the need for employee training. It facilitates to improve the performance of the employees and provides information to the organization about the skills they possess.

\section{Objective of the Study}

- To analyze the employee competency at Training \& Development Department of a Typical Manufacturing company in Mysuru.

- To identify the competency gaps among employees of a Typical Manufacturing company.

- To give necessary recommendations to bridge the gaps.

\section{Research Design and Methodology}

Research design and methodology of the study involves the following stages:

- Data Collection

- Sampling Method

- Sampling Design

- Methodology

- Factors Considered for the study

- Analysis

- Findings \& Recommendations

- Conclusion

- References

\section{Data Collection}

The primary data was collected through survey questionnaire and discussions were held with the functional managers, immediate superiors and departmental heads.

\section{Sampling Method}

The study carried out a Census survey. Hence, the entire population was considered for conducting the research.

\section{Sampling Design}

Twelve employees at various designation of the department were taken, that comprises of a Manager, two Administrative Coordinators, four Training Coordinators, one IT Coordinator, one Faculty and three Supervisors.

\section{Methodology}

Different Questionnaires were prepared according to the designations. The actual values were derived from the answered questionnaires. Whereas, the rating scales, expected values and the weightage were assigned to an individual by their immediate superiors or manager or the head of the department. Later, gaps were identified and the individual competency maps were drawn. 


\section{Factors Considered for Study}

- Values and Ethics

- Vision and Purpose

- Commitment

- Communication Skills

- Creativity

- Team Work

- Passion

- Interpersonal Skills

- Connectivity

- Planning

- Knowledge Level Competencies

- Skills and Attributes

- Job -related Competencies

\section{Analysis}

The study considered 12 employees of different designations of the department that includes - a Manager, two Administrative Coordinators, four Training Coordinators, one IT Coordinator, one Faculty \& three Supervisors. The employee competency maps are as follows (Figure 1 to Figure 12):

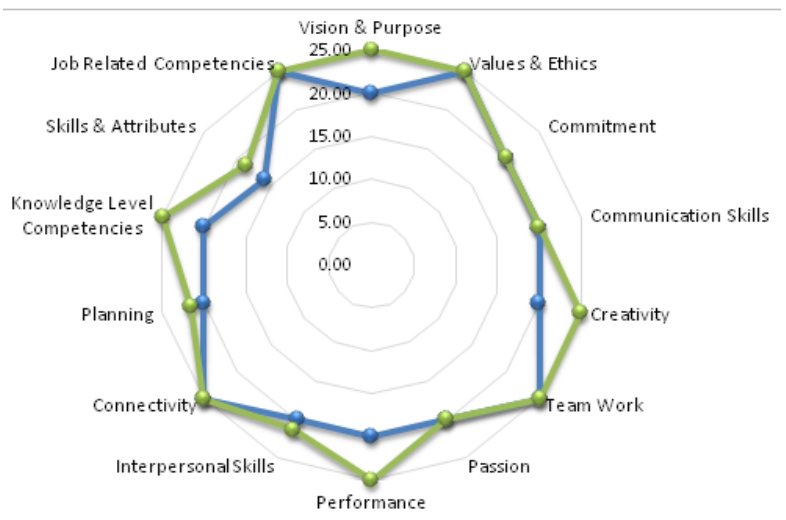

Figure 1. Competency map of manager.

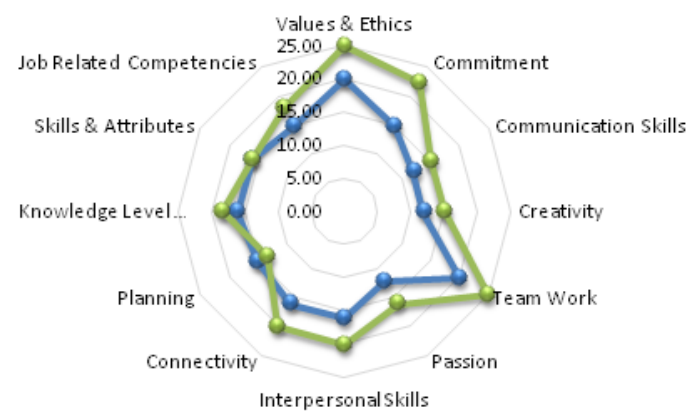

Figure 2. Competency map of admin coordinator 1.

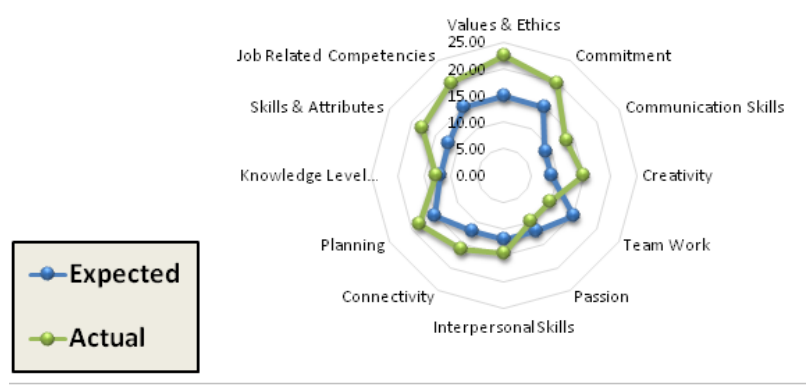

Figure 3. Competency map of admin coordinator 2.

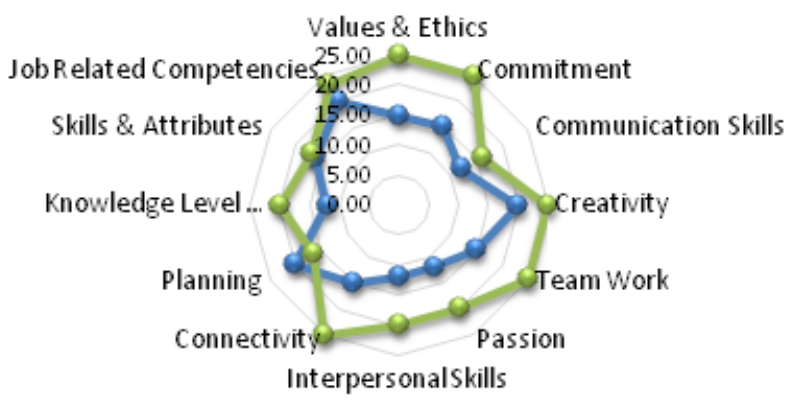

Figure 4. Competency map of training coordinator 1.

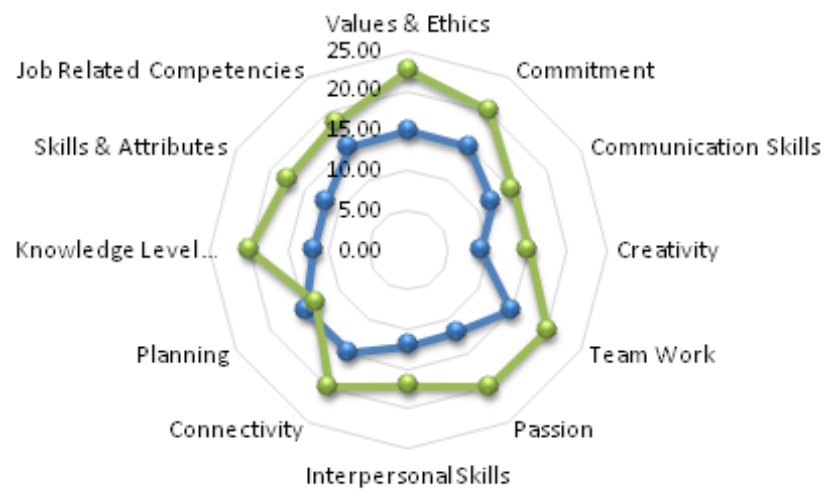

Figure 5. Competency map of training coordinator 2 .

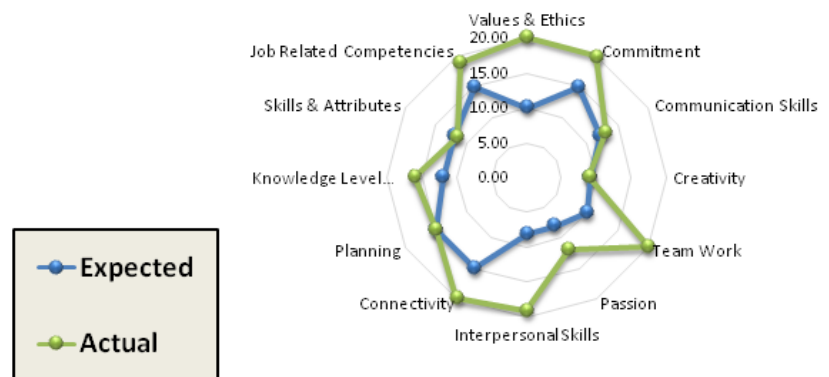

Figure 6. Competency map of training coordinator 3. 


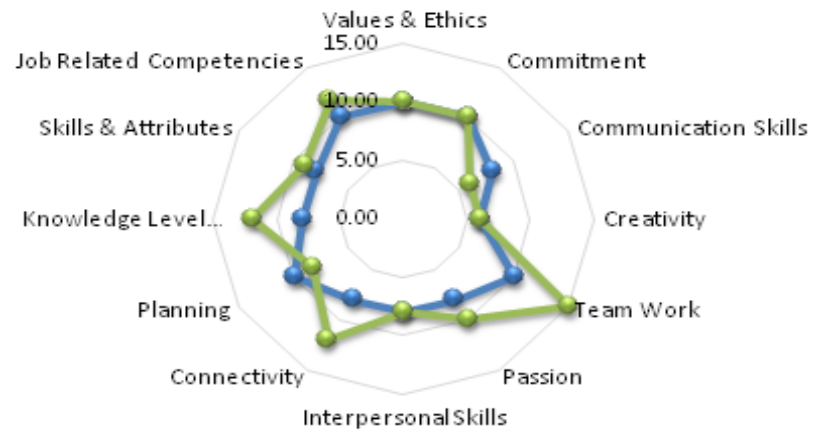

Figure 7. Competency map of training coordinator 4 .

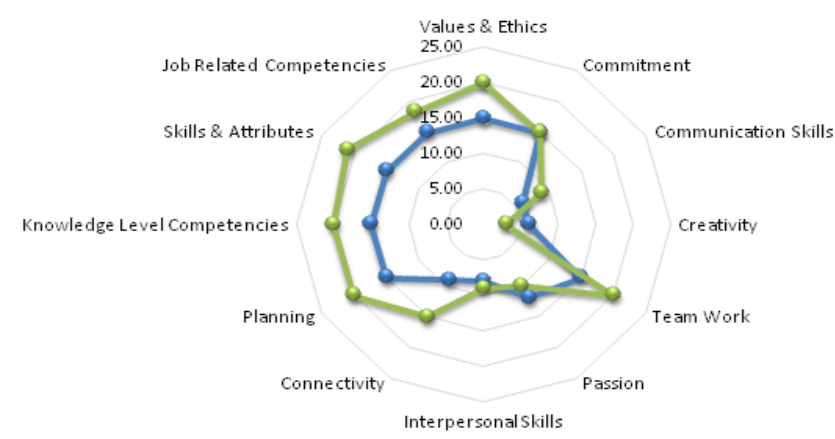

Figure 8. Competency map of IT coordinator.

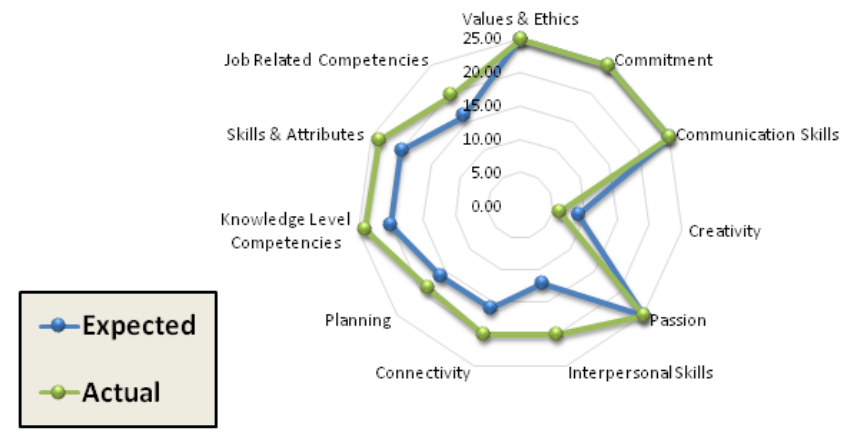

Figure 9. Competency map of trainer.

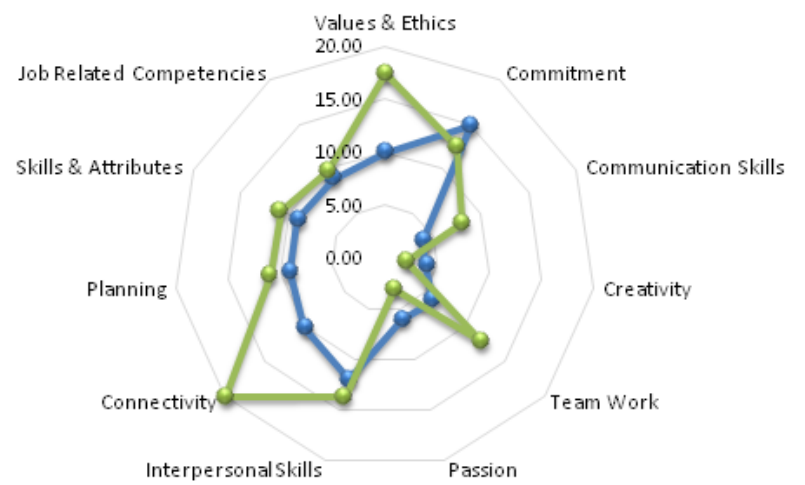

Figure 10. Competency map of supervisor 1.

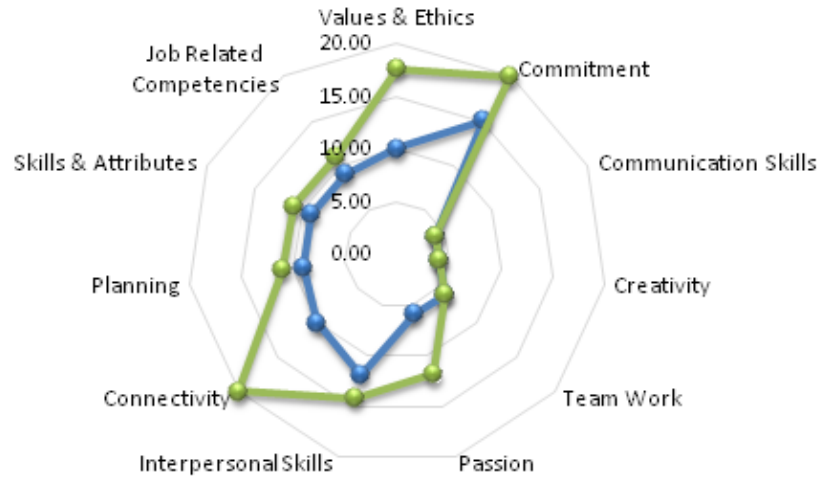

Figure 11. Competency map of supervisor 2.
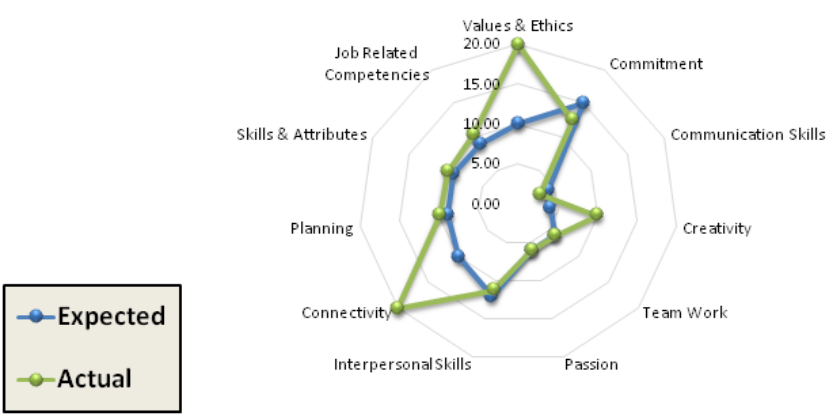

Figure 12. Competency map of supervisor 3.

\section{Findings \& Recommendations}

On the basis of results obtained from competency analysis, following suggestions/Recommendations are given (Table 1).

\section{Conclusion}

The competencies of all the 12 employees of the Training and Development Department of a manufacturing company in Mysuru were successfully mapped. On an average, the employees have higher actual values when compared to the expected values. Thus, the efficiency $\&$ the competency of the mapped department is high. 
Table 1.

\begin{tabular}{|c|c|}
\hline Designation & Areas Recommended For Training \\
\hline Manager & Emotional resilience \& Stress Tolerance \\
\hline Admin Coordinator 1 & $\begin{array}{l}\text { Planning, Time Management, Assertive Communication, Stress Tolerance, Mental Agility, Negotiation Skills, Fund allocation } \\
\text { \& Fund Management }\end{array}$ \\
\hline Admin Coordinator 2 & Team Work, Passion, Flexibility, SAP, Planning, Pro-activeness, Fund allocation, Fund Management \& Negotiation Skills \\
\hline Training Coordinator 1 & $\begin{array}{l}\text { Assertive Communication, Planning, Stress Management, Time Management \&Analytical, problem-solving and decision- } \\
\text { making skills }\end{array}$ \\
\hline Training Coordinator 2 & $\begin{array}{l}\text { Communication without hesitation, assertive communication, Flexibility, Planning Stress Management, time management, } \\
\text { Adaptability \& Detail Consciousness }\end{array}$ \\
\hline Training Coordinator 3 & $\begin{array}{l}\text { Communication skills, passion, planning, Assertive Communication, Stress management, Analytical, problem-solving and } \\
\text { decision-making skills, Mental Agility, Time management }\end{array}$ \\
\hline Training Coordinator 4 & $\begin{array}{l}\text { Values \& ethics, Commitment, Communication Skills, Creativity, Passion, Receptive to Corrections, Flexibility, Planning, } \\
\text { People management Skills, Mental Agility, Pro-activeness, time management, Self-Management, \& Organizing }\end{array}$ \\
\hline IT Coordinator & $\begin{array}{l}\text { Code of Conduct, Commitment, Effective Communication, Creativity, Passion, Receptiveness to Corrections, Confidence to } \\
\text { face defaults, Flexibility, Mental Agility, Time Management \& Updated with Software }\end{array}$ \\
\hline Trainer & $\begin{array}{l}\text { Creativity, Assertive Communication, Analytical, problem solving and decision-making skills, Meet heterogeneous } \\
\text { expectations of trainees }\end{array}$ \\
\hline Supervisor 1 & $\begin{array}{l}\text { Commitment, Creativity, Passion, Flexibility, Adaptability, Pro-activeness, Interpersonal Skills, Assertiveness, decision- } \\
\text { making skills and Time Management }\end{array}$ \\
\hline Supervisor 2 & $\begin{array}{l}\text { Social skills and abilities, Communication Skills, Creativity, Team Work, Stress Tolerance, More of Analytical, problem } \\
\text { solving and decision-making skills }\end{array}$ \\
\hline Supervisor 3 & $\begin{array}{l}\text { Commitment, Communication Skills, Interpersonal skills, Social skills and abilities, Analytical, problem solving and decision- } \\
\text { making skills, Team Work, Passion, Flexibility, Assertiveness, Stress Tolerance, Adaptability and cost management }\end{array}$ \\
\hline
\end{tabular}

\section{Bibliography}

Balaji, S., \& Vimala, D. (2012). A Study on Competency Mapping in Adecco Service Organizations, Chennai. IRJC, Asia Pacific Journal of Marketing \& Management Review, 1(3). ISSN 2319-2836

Jain, V. K. (2013). Competency Mapping in Indian Industries - A Case Study. International Journal of Emerging
Research in Management \&Technology, 2(10). ISSN: 2278-9359

Kaur, J., \& Kumar, A. (2013). Competency Mapping: A Gap Analysis. International Journal of Education and Research, 1(1).

Yuvaraj, R. (2011). Competency Mapping - A Drive for Indian Industries. International Journal of Scientific \& Engineering Research, 2(8). 